\title{
La constitución del individualismo en el Perú. Notas introductorias
}

\author{
Julio Mejía Navarrete \\ Universidad Ricardo Palma \\ julio.mejia@urp.edu.pe
}

\begin{abstract}
RESUMEN
El trabajo pretende analizar la constitución del individualismo en el Perú, su desarrollo desde inicios del siglo XX hasta el presente y a partir de allí intentar apuntar algunas tendencias del futuro. Se presenta un ensayo de interpretación sobre la formación del individualismo que permita bosquejar algunas ideas para ordenar un debate mayor.

En los estudios sociales del país el proceso del individualismo fue menoscabado para subrayar la dimensión estructural de la modernización. Interesa entregar una imagen que procure explicar la modernización desde el ángulo de la configuración del individuo en el Perú contemporáneo. Sin embargo, recientemente el individualismo ha despertado un interés más teórico, dejando de lado el estudio de su evolución en la sociedad.
\end{abstract}

Palabras clave: Individualismo, modernización, sociedad de consumo, comunidad, buen vivir.

\section{The individualism constitution in Peru. Introductory notes}

\begin{abstract}
This work aims to analyze the individualism constitution in Peru, its development from the early twentieth century to the present and from there try to point out some trends for the future. An interpretation essay on the formation of individualism is presented, which allows us to sketch some ideas to organize a larger debate.

In the social studies of the country, the process of individualism was undermined to emphasize the structural dimension of modernization. It our interest to present an image that tries to explain modernization from the point of view of the configuration of the individual in contemporary Peru. Even though, recently individualism has awakened to a more theoretical interest, leaving aside the study of its evolution in society.
\end{abstract}

KeYwords: Individualism, modernization, consumer society, community, good living 


\section{Introducción}

El individualismo se ha privilegiado como un tema central de los teóricos clásicos y recientes de la modernización del mundo. ${ }^{1}$ Es un rasgo esencial del desarrollo de las sociedades modernas para comprender su génesis del siglo XVI, su desarrollo posterior y su transformación en el siglo XXI. De esa forma, el individualismo se revela como parte intrínseca y determinante del contenido de la modernidad.

Sin embargo, en el Perú la constitución del individualismo moderno tiene una historia reciente, gira alrededor del proceso de la crisis del Estado oligárquico y el desarrollo de la globalización neoliberal. En particular, destacamos los antecedentes del individualismo cholo a principios del siglo pasado, la expansión del individualismo social con las masivas migraciones andinas de los sesenta y la hegemonía del individualismo egocéntrico neoliberal. Desarrollos de individualismo que abren las posibilidades a originales formas de individuación y autonomía societal.

\section{Antecedentes del individualismo peruano. Movilización del cholo}

La sociedad peruana hasta la primera mitad del siglo pasado implicó el desarrollo inicial de un cierto individualismo cholo (Bourricaud, 2012), todavía muy fragmentado y de carácter limitado, que respondía a la hegemonía de la sociedad oligárquica y la exclusión de las mayorías poblacionales indígenas. No obstante, era una dinámica que anunciaba la desintegración de la sociedad estamental. En el largo y complejo germinal del individualismo coexistían al mismo tiempo valores tradicionales y valores modernos.

Situación que correspondía a la persistente herencia de la colonialidad, la población se estructuraba en torno de la idea de la raza-etnicidad, se reducía a la condición "india" y al dominio oligárquico sobre todas las formas de trabajo, principalmente del régimen servil en el campo y de la servidumbre doméstica en las ciudades que, de acuerdo a las estimaciones del censo de 1876, comprendían el 57 por ciento de la población (Contreras, 1996, 7). Las grandes colectividades no solo estaban socialmente impedidas de participar en el proceso de individualización, por su condición de trabajadores campesinos serviles y, además, porque no habían dejado de ser consideradas poblaciones "racialmente" clasificadas como "inferiores", dada su condición de indios y negros. En esta sociedad estamental, el indio "individual no contaba como 'individuo' sino como miembro de una asociación" (Dülmen, 216, p. 138), pueblo o comunidad y, sobre

1 Puede consultarse entre otros, Weber (1984), Simmel (1986), Durkheim (1898), Elías (1987), Dumont (1987), Bauman (2005), Beck y Beck-Gernsheim (2001), Castells (2009) y Lipovetsky (1986). Entre algunas interpretaciones teóricas, destacan Béjar (1990), Martuccelli (2015), Mejía (1988). 
todo, para la sierra del Perú donde movilizarse y abandonar el mundo indígena rural era casi imposible.

Los antecedentes del individualismo pueden encontrarse en la "aparición del cholo" (Bourricaud, 2012, pp. 34-36) que se movía en los intersticios de la sociedad oligárquica. Resultado de la expansión de las actividades mercantiles, lanas en el sur, cańa de azúcar norte y cobre en el centro, y el crecimiento poblacional que pasó de 2'699,106 en 1876 a 6’207,967 en 1949 (Seminario, 2015), originando nuevas capas medias y populares urbanas y un inicial proceso de individualización. La "existencia individual" (Bourricaud, 2012, p. 203) del cholo se gesta en el seno de la sociedad oligárquica, aparece como dispar de la sociedad dominante y como suplemento en relación a ella, representa a un "individuo que asciende, que cambia”. En esta perspectiva, el individuo se constituye en un proyecto inconcluso, pero en marcha. El cholo expresa tempranamente la gestación de relaciones de intercambio mercantil y, al mismo tiempo, delimita la frontera entre lo urbano con lo campesino y lo indígena con el mundo gamonal.

El relativo individualismo cholo que se desarrolla en los márgenes de la sociedad, en las orillas de las formas de explotación y dominación hegemónica que la oligarquía impuso en la sociedad peruana. El individualismo cholo representó la disgregación limitada de la sociedad indígena; el cholo "es un viajero", se moviliza a la ciudad, "Anda siempre por los montes y los valles" (Bourricaud, 1989, p. 82), como un acto de negación del tradicional estatus campesino indígena. Asimismo, la aparición del cholo posibilitó la gestación del egoísmo como una conducta orientada por el pragmatismo que lo utilizó para "entrar en todos los empleos de lo que se pueda ofrecer" (Bourricaud, 2012, p. 55). Sin embargo, el cholo seguía siendo indígena en el contexto de la expansión de las ciudades, no alcanzaba romper con la clasificación de la población marcada por la condición racial, era un "mestizo aindiado"(Svampa, p. 50) que cargaba con todos los defectos de la naturaleza de indio y, además, no rompía sus vínculos con sus comunidades y la cultura andina — trabajo, reciprocidad, paisanaje- que les sirven para su entrada en la sociedad urbana y, a la vez, impedían el desarraigo individual y la llegada de la anomia social.

Asimismo, el cholo continuaba siendo indio y el individualista era exclusivamente masculino, las mujeres indias no eran parte del proceso; para ellas solo quedaba la exclusión en los pueblos, las comunidades indias y en el trabajo servil doméstico de las ciudades. La gestación del individualismo en el Perú es indio, masculino y urbano. Lo cholo supuso el inicio de un proceso de descentramiento, demográfico y político del país, de la sociedad oligárquica y rural al anuncio de un país urbano y cholificado. Con todas sus limitaciones, el mestizaje individualista significaba un privilegio ganado al orden oligárquico por una nueva categoría social relativamente restringida.

En un orden de dominación cerrado, la movilidad social era un fenómeno diminuto, sancionado por su posicionamiento clasista y descalificado por la distinción étnico- 
cultural como arribista en las ciudades de la costa y mal visto en las ciudades de la sierra. El mestizaje y el cholo eran despreciados por la sociedad oligárquica, en las ciudades costeńas, de modo particular en el crecimiento de Lima a comienzos del siglo XX, la movilidad social de los sectores populares para las élites criollas blancas, señoriales y oligárquicas, era de mal gusto, ridícula y desprestigiada como huachafo (Neira, 1993). Hasta en los sectores opuestos a la sociedad oligárquica el mestizaje generaba "el rechazo de intelectuales indígenas" que iban desde la prédica de Huamán Poma hasta Luis E. Valcárcel (Montoya, 2010, p. 454). El individualismo y la movilidad social no se podían constituir en una práctica social generalizada, se carecía de legitimidad de la sociedad, era vilipendiado por la sociedad oligárquica.

En ese sentido, el cholo solo tiene "existencia individual" en relación al mundo campesino-indígena y, a la vez, se encontraba bloqueado con respecto de la sociedad dominante que no lo aceptaba y se oponía activamente por su condición "natural" de indio. El orden social estamental generó que la "existencia individual" de los cholos se vean sitiados de ejercer plenamente la libertad y autonomía personal. El cholo expresaba un cierto individualismo que muestra el desplazamiento horizontal desde lo indígena, pero, al mismo tiempo, impedía su movilidad vertical entre grupos diferentes por la hegemonía de la sociedad oligárquica. La explicación a este proceso puede encontrarse en el dominio del discurso racista que permitió hasta los años setenta reproducir un orden social fundado en estamentos; el vértice de la pirámide estaba detentado por la población de origen blanca oligárquica y el resto por indios, negros y cholos de razas inferiores, que funcionaba como compartimientos estancos, con escasas posibilidades de interrelaciones permanentes y movilidad social. A pesar de todo, el cholo y el mestizaje intentaban gestar una conducta inédita y contradictoria: los individuos solamente pueden confiar en lo que tienen y procuraban hacerse dueños de su destino: camino que marcaría el futuro próximo de Perú.

\section{Migración, modernidad e individualización social}

En el Perú la expansión del individualismo social se relaciona directamente con la migración masiva de las poblaciones indígenas, la fundación de barriadas urbanas, la difusión de la informalidad, la esperanza del progreso y la presencia de valores andinos, proceso que tiene como punto definitivo en la crisis del estado oligárquico.

La crisis del estado oligárquico se traduciría en la desarticulación de las relaciones serviles y semiserviles, la desintegración de las estructuras de autoridad local y estatal ligadas al poder de la burguesía y los terratenientes señoriales, como resultado de la masiva movilización de los campesinos indios entre 1957 y 1969, y de las medidas de redistribución de tierras de la reforma agraria en los años de 1969-1975. La transformación 
de la ciudad y del mundo andino se expresa en el proceso de movilidad espacial de los andes a la ciudad o de los andes a Lima. La migración tiene características estructurales muy intensas; no solo fue el desplazamiento individual de la poblacional de la sierra a la costa; representó el comienzo de una dinámica de modernización que contribuyó a modificar el orden oligárquico y a desarrollar la sociedad nacional del Perú del siglo XXI.

En ese sentido, la migración significó una decisión moderna del campesino migrante, aventurarse a lo desconocido y descubrir una fe por el futuro. Algunos autores desarrollan la categoría de "sujeto migrante" (Cornejo, 1995) y Carlos Franco (1991, pp. 45-46) llamó la atención del acto de migrar como un proceso de liberación moderna de la subjetividad en el Perú. La migración era la realización de una trayectoria individual, como parte del proceso de movilidad social del campo a la ciudad. La migración implicó la constitución de la idea de progreso en las personas, modificó radicalmente la mentalidad estamental que concebía la vida como autárquica, estática y perdurable en el largo tiempo. La búsqueda de progreso y desarrollo de la autonomía individual va orientar un itinerario lleno de incertidumbre, sacrificios, penalidades y esfuerzos de las personas por salir adelante en la ciudad (Adams y Valdivia, 1991). Desde entonces, la subjetividad del cholo y mestizo migrante se individualiza, rompe paulatinamente con la posición que el indígena no contaba como individuo en el régimen oligárquico, simplemente era un miembro más del orden de la comunidad o pueblo. La gestación del individualismo supuso un cambio cultural modernizante, representó la esperanza del progreso de las personas migrantes porque anunció la liberación de los individuos de sus ligamentos estamentales y, primordialmente, les permitió reflexionar en una trayectoria biográfica signada por la autonomía personal.

El migrante encuentra en la ciudad, en especial de Lima, una sociedad que los margina y excluye, al llegar no solo se carece de recursos económicos y materiales, sino que se enfrenta a una cultura oligárquica distinta. En gran parte, las ciudades de la costa peruana y Lima seguían siendo ciudades fracturadas y fragmentadas, marcadas desde sus comienzos coloniales por la división segmentada y diferenciada étnicamente entre indígenas, mestizos y negros, frente a los limeños citadinos de origen criollo blanco en el vértice del poder. Las ciudades de los cincuenta y sesenta marginaban a los migrantes y los condenaban a vivir en asentamientos humanos, en los márgenes de la ciudad. Lo indígena es menospreciado y discriminado por la cultura criolla hegemónica. En esas condiciones, el campesino migrante llega con su único capital simbólico, la cultura andina, en particular trae consigo una ética del trabajo y las relaciones comunitarias. No se trata solo de un hecho económico sino principalmente de que la cultura andina, en particular la instancia comunitaria es la que socializa a sus miembros en actitudes orientadas a la colaboración y minimiza los riesgos, que de otro modo tendrían que enfrentarse únicamente en forma aislada, factor central en la movilización de esfuerzos de los campesinos o migrantes para dar una respuesta eficiente al mercado (Bonilla, 2005). 
En condiciones de marginación y exclusión social del migrante en las ciudades principales del país y dotados de una cultura andina del trabajo, la informalidad ${ }^{2}$ representó el mecanismo que permitirá a los individuos cholos apostar por el anhelado progreso económico. En términos más concretos, la informalidad es la respuesta social del migrante para lograr sobresalir en la ciudad en un contexto de exclusión, violencia y pobreza. La informalidad no solo representa la expansión de un negocio y la pequeña propiedad en condiciones de ilegalidad; fundamentalmente significa el medio para hacer frente a la lógica del patrón-cliente, la marginación étnica-racial de las élites oligárquicas, al impedimento de participar en la sociedad del Perú "oficial", a la negación de los derechos ciudadanos, violencia permanente y la condena de vivir en pobreza. La cultura excluyente oligárquica fue respondida, en buena medida, por una cultura de la informalidad a la autoridad. La discriminación y exclusión dio lugar al desacato de la informalidad. El migrante recrea "espacios seguros" para "separarse, apartarse" y donde la sociedad oligárquica "no puedan acceder" fácilmente y lo avasalle (Zibechi, 2015, p.115), deja de lado las pautas definidas por la ley o las normas oficiales y las transgrede para actuar en un mundo informal diferenciado, se apoya en los recursos culturales de origen andino y en las nuevas pautas mercantiles que ofrece la ciudad, para salir adelante y no caer en la anomia. La informalidad conserva mucho de la antigua cultura andina en el medio urbano, dispone de una ética del trabajo, recrea las relaciones de paisanaje, relaciones comunales y de solidaridad. Asimismo, la informalidad es la utilización de la "tremenda energía... disciplina, capacidad de trabajo y de las técnicas de trabajo y de las reglas de mercado" (Quijano, 2009, p.44), de la expansión de la pequeńa propiedad y de formas empresariales. En ese sentido, la difusión de la pequeña producción informal delimita el individualismo cholo, quien se permitió romper con la cultura estamental que condenaba la vida indígena a la sola búsqueda de la subsistencia y a la negación de toda aspiración de riqueza. Este, en los asentamientos humanos de las ciudades, es capaz de tejer nuevos lazos personales fundados en valores tradicionales andinos y en el aprendizaje de los patrones de trabajo, del mercado y, sobre todo, expresó el desarrollo de una mentalidad fundada en la búsqueda constante del interés propio.

Por otra parte, en la sociedad de las barriadas la experiencia individual se organizaba en función de pautas relativamente estables, de largo plazo y racionales del trabajo duro, el tiempo se definía por los avances de la edificación de la vivienda estimada en un promedio de 15-20 ańos (Riofrío y Driant, 1987, pp. 73-78), llevado bajo la forma de autoconstrucción, con intervención de la familia y de la comunidad. En las barriadas las personas orientaban su consumo según sus necesidades y disponibilidades económicas.

2 La influencia de la cultura andina en el desarrollo moderno, destacando el surgimiento de un empresariado de origen migrante de la sierra peruana, asentado en la ciudad de Lima y otras del país. Las experiencias empresariales de Gamarra, el Parque Industrial de Villa El Salvador, El Trébol de Caquetá, el Centro Comercial Unicachi e Infantas en Lima; los zapateros de El Porvenir en Trujillo; y los puneńos en Arequipa (Huber 1998). 
Si se deseaba algo o construir la vivienda había que esperar, se buscaba tener ahorros y tenían que trabajar duro, el consumo se alineaba según las posibilidades de las personas. Los individuos orientaban su consumo no solo como un acto de compra sino, fundamentalmente, lo definían según el manejo minucioso de sus necesidades, recursos detentados y del valor de las gratificaciones postergadas. Se trataba del predominio de una evidente racionalidad, que seguía la lógica del homo económicus, basada en el cálculo de los medios indispensables para lograr el mejor resultado. La constitución del individualismo tiene uno de sus ejes centrales en la racionalización de la conducta de la vida de los migrantes andinos que supone la elección de la ética del trabajo como medio esencial para llegar a un fin determinado: el progreso, tiende a dejar de lado gradualmente la cultura del sufrimiento fatalista del gamonalismo y el impulso milagroso de la religiosidad en el destino de las personas (Portocarrero, 2007).

La formación del individualismo social en los barrios populares y las barriadas no solamente fueron el resultado del fenómeno migratorio sino, lo más importante, es que la población migrante comienza a redefinir el carácter de la propia sociedad. Las nuevas comunidades urbanas se transformaron en el estilo de vida preponderante de las ciudades, son las sedes de las nuevas clases medias y populares emergentes del país y el desarrollo de un proceso de mestizaje que modificó todo el panorama social del país. ${ }^{3}$ Paralelamente, la población de origen andina asentada en barrios precarios delimitaba un proceso de autonomía política, traía la búsqueda de derechos sociales y el desarrollo de una identidad, que se definió como el proceso de cholificación (Quijano, 1980). Era la cultura que se basaba en la realización de los individuos por medio del trabajo, se quería empleo y familia, pero a la vez se aspiraba al bienestar de la comunidad, el bien común asociado a la organización y participación barrial, que se expresaba en querer hacer de los asentamientos humanos barrios urbanos integrados a la ciudad, el interés de las personas pasaba de lo individual a lo claramente social. La cholificación era parte de un proceso de conquista de un espacio de formación de ciudadanía, desarrollo de una comunidad nacional ${ }^{4} \mathrm{y}$ expansión de una forma de individualización de la sociedad peruana.

En el Perú, el individualismo social es resultado de la transformación societal y de los avatares del propio sujeto migrante en las barriadas de las ciudades, es parte de la movilización de la población andina y no tiene que ver con el desarrollo "institucional" previamente existentes. En la sociedad peruana sesentera se desarrolla un individualismo social cholo. El individualismo social se constituye directamente por la migración

3 Actualmente, la población de Lima se encuentra conformada por un 36.2\% de migrantes directos, $43.5 \%$ de segunda generación, con padres y abuelos migrantes, 7.6\% de tercera generación, con padres limeńos y abuelos provincianos y 12.7\% de limeńos, padres y abuelos de la capital (Arellano 2004, 91).

4 Puede consultarse sobre desarrollo de la ciudadanía popular en Carlos Iván Degregori, Cecilia Blondet y Nicolás Lynch (1986), Carlos Franco (1991) y, recientemente, José Matos (2012). 
andina masiva que trajo la creencia en el progreso personal, la herencia cultural comunal en la formación de las barriadas, la difusión creciente de la pequeńa propiedad informal y la confianza racional en el trabajo duro para salir adelante.

\section{Del individualismo social al individualismo egocéntrico}

Las corrientes migratorias a la ciudad transforman la sociedad peruana y puntean el destino del individualismo. Trazan una evolución del individualismo social de los ańos sesenta y setenta a un individualismo "egocéntrico" neoliberal de las últimas décadas. De esa forma, el individualismo es hechura de una rara mezcla de la desintegración de la cultura oligárquica y de la hegemonía de la cultura privatista de la globalización neoliberal.

La sociedad global que se expande en los últimos años experimenta una evolución radical que reorienta la responsabilidad dirigida a los otros, por el impulso del individualismo en una "responsabilidad ante uno mismo y... hacia uno mismo" (Bauman, 2010, p. 80). El individualismo reduce el compromiso con los demás o no le interesa, busca solo el interés personal, solo tiene presencia "las necesidades, deseos y proyectos de cada individuo" (Castells, 2009, p. 166). El individuo en la sociedad global se ha librado de los últimos constreñimientos estructurales socializantes que impedían su total emancipación, las instituciones se cuestionan y reducen su actuación, la disminución del peso del Estado, de las clases sociales, del poder de la vecindad, la familia, las grandes ideologías dejan de ser vehículos de proyectos históricos, las creencias utópicas se desacreditan, pareciera que se desarrolla una sensación de "era del vacío" (Lipovetsky, 2003) o de "la sociedad ya no existe" (Touraine, 211), se genera un deterioro constante de los vínculos sociales, de las solidaridades y, al mismo tiempo, hay un proceso de atomización, los comportamientos tienden a aislar a las personas.

El abandono del compromiso emocional con los otros no desemboca en un individualismo absoluto, sin vínculos sociales, más bien genera que las personas conciban los lazos entre ellos en términos puramente mercantiles, interesa solo la búsqueda del beneficio exacerbado de las relaciones con los otros. Las interacciones sociales pierden su contenido emocional y se convierten en puros compromisos. Edgard Morin (y Ceruti, 2013, p. 101) lo explica en términos de las transformaciones del patrón moderno global: "El individualismo generado por la persecución unilateral del propio éxito desemboca fácilmente en la pérdida del sentido de interés colectivo, en el puro egocentrismo y en la desaforada sed de lucro". En general, la sociedad se orienta por el egocentrismo y la vida social gira en torno del individuo. Se trata de un individualismo privatista, defensivo y la responsabilidad se restringe a uno mismo, se basa en el egoísmo y en la búsqueda desbocada del beneficio propio. 
El desarrollo del capitalismo globalizado en el país está llevando a un proceso intenso de re-clasificación social de la población, conjuntamente con la expansión de nuevos sectores medios y populares se expande de modo creciente la cultura de privatización y el individualismo extremo que ocurren en un mundo de incesante violencia y destrucción del "capital social" (Bourdieu, 1980), donde el afecto y la confianza resultan disfuncionales para la sociedad y se pierde la energía colectiva que puedan generar las interacciones de respeto, disfrute de la compańía de los otros y la fortaleza de la comunidad.

El tránsito de una cultura que tenía como fuente principal de su vitalidad el desarrollo barrial, el interés comunitario y el esfuerzo individual/colectivo a una "cultura de privatización" y dominación puramente individualista, se explica por la reciente historia del Perú. Una de las razones se puede encontrar en la inmensa perturbación social que generó el movimiento subversivo Sendero Luminoso en los noventa, cubriendo toda la sierra y parte de barrios marginales del país ocasionó la muerte de 69,280 personas (CVR 2003, Anexo 2, p. 13), en su mayoría de pueblos de origen indígena, alterando la vida comunal, liquidando dirigentes, destruyendo organizaciones de base, disgregando el tejido social y llevando a los individuos a interesarse solo en la sobrevivencia. Otra explicación, interrelacionada, se encuentra en la profunda mercantilización globalizada de la sociedad peruana impulsada desde 1980 a la actualidad, especialmente durante el gobierno de Fujimori en los años noventa, que prácticamente privatizó todo y la vida social casi desapareció, se liberalizó los servicios públicos y buscó hacer del interés personal el único compromiso societal. Procesos que llevaron a las gentes a una comprensible desmoralización y a un vacío espiritual que fue impregnado por una cultura neoliberal global, exclusivamente, individualista de la existencia social.

La modernidad neoliberal en el Perú reestructura el imaginario social, la vida cotidiana, los valores y lleva que la vida de las gentes se oriente por "considerar superflua toda ley civil o moral" (Todorov, 2014, p. 77). El otro solo existe como un obstáculo o es un medio en el camino de la búsqueda del éxito personal, la cultura transforma los vínculos entre las personas en relaciones puras sin frenos sociales ni morales, sin límites ni regulaciones, desaparece toda consideración a la comunidad y toda causa común. Con razón, Aníbal Quijano (2011, p. 82) señala que es "la conducta egoísta travestida de libertad individual" el nuevo ideal de la modernidad global. Mientras que la libertad de la modernidad global se restringe al individualismo, a la mercantilización de la sociedad y a un mero horizonte egoísta.

De la misma manera, el individualismo es producto del desmoronamiento de la sociedad oligárquica en el Perú. El individualismo reproduce y se funde con el lado más mísero de la arcaica cultura oligárquica la "viveza" criolla, dejando de lado la "gracia" y distinción señorial. De la cultura del gamonalismo se recrean sus expresiones más cercanas con los tiempos individualistas la "prepotencia" y la "fuerza", mientras que no se toman en cuenta la "delicadeza" y el paternalismo (Quijano, 2009, pp. 14-25). De 
esa forma, el individualismo peruano se encuentra pautado por la "viveza" criolla, la maña y picardía que buscan manipular las cosas en beneficio exclusivamente personal para obtener una ventaja inmediata sin tener en cuenta o, simplemente, viola la ley y las normas morales. La "viveza" criolla solo puede existir en un contexto social donde predomina la manipulación, la agresión, la fuerza e incesante violencia de la vida cotidiana individualista.

En el Perú contemporáneo, el individualismo se entrelaza con la subjetividad del neoliberalismo global, el pragmatismo utilitario y la complacencia desmedida por la mercantilización de la vida social. El resultado actual es un individualismo egocéntrico, donde predomina la viveza criolla, la violencia, el pragmatismo utilitario y la mercantilización.

\section{Conclusión. Las posibilidades del individualismo contemporáneo}

Los procesos de la constitución del individuo en la sociedad contemporánea muestran que cada momento histórico definen un carácter específico, marcados por el trance entre individualismo y comunalismo (Castells, 2009). Las posibilidades de la evolución futura se relacionan con el tipo de sociedad y con el conjunto de interacciones entre los integrantes. Cada vez más interrelacionados, destacan los siguientes caminos: el individualismo egocéntrico, la individuación y la autonomía societal.

La primera posibilidad es la subsistencia del individualismo egocéntrico en una sociedad decantada por la globalización neoliberal. Desarrollo que deriva cada vez más en la hegemonía de un discurso ideológico del "yo emprendedor" (Beck y BeckGernsheim, 2001, p. 29), que recurre a las imágenes de individuos que dependan solo de ellos, pequeńos productores, trabajadores mestizos y cholos, desde sus potencialidades se construyen sin exigir casi nada a las instituciones sociales. La subsistencia del individualismo egocéntrico solo sería posible en un nuevo periodo de colonización bajo el dominio de los Estados Unidos (Quijano, 2001).

La permanencia del individualismo deviene un individualismo ilusorio, que para actuar necesita del descrédito de lo social y la justificación de la sociedad como la suma de intereses individuales. Sin embargo, la estructura social neoliberal es profundamente inequitativa y desigual (Piketty, 2014), el mercado no facilita los medios para que las mayorías de individuos puedan desarrollarse de manera independiente y menos puedan autoemprenderse. La hegemonía del individualismo no necesita de organizaciones intermedias en las relaciones de intercambio y la vida social, solo demanda de individuos aislados para enfrentarse en el trabajo, la pequeña propiedad y las exigencias de la cotidianeidad. En realidad, la sociedad y el mercado desarrollan un individualismo "sin derechos", solo interesado en que "cada uno pueda seguir su propio camino, y la 
posibilidad de que todos lo hagan en paz" y, de esa forma, minimizar el poder público a la protección de la "seguridad de las personas físicas y sus propiedades" (Bauman, 2005, p. 41). En esas condiciones, la sociedad puede devenir en un mundo atomizado y sin brújula moral.

Otra posibilidad es el proceso de "individuación” (Castells, 2012, p. 220). La individualización social busca que las personas sean parte de comunidades que respondan a sus identidades particulares. Redes de comunidad que van desde seguidores de un club deportivo, "economías étnicas", mujeres, medio ambiente, pacifistas, etc., como formas de "socialidad" basadas en relaciones emocionales de sentirse juntos en la búsqueda de nuevo sentido que rompa con el individualismo (Mafesoli, 1990). El legado cultural andino dirigido a la acción colectiva e ideales compartidos vuelve a ser un punto fundamental de la organización de la vida social. Las comunidades en redes sociales se convierten en "espacios de la autonomía" individual, de libertad: comparten valores comunes, favorece colaboración y solidaridad. Las comunidades son espacios de los intereses individuales que actúan dentro de los límites institucionales de la sociedad, que define el accionar de la propia autonomía.

La individuación es el desarrollo del individuo con una fuerte ligazón a la comunidad y con una conciencia clara de los intereses y obligaciones que giran alrededor de las instituciones de la sociedad moderna. Las comunidades de individuos buscan "repoblar el espacio público" (Bauman, 2005, p. 45), hombres y mujeres se organizan para defenderse frente a la privatización, la vulnerabilidad o la inseguridad del mundo. En la última década se gesta la "cultura de la autonomía que caracteriza a la sociedad" (Castells, 2017, p. 301), emerge una heterogeneidad de asociaciones, los individuos vuelven a debatir y negociar entre las ventajas personales y el bien colectivo, transitan hacia una ciudadanía que exigen derechos que nacen de la autoafirmación y autonomía de la asociatividad, que demanda intereses personales en compatibilidad con los intereses en común. Como se trata de redes sociales, se encuentran condicionadas por los resortes tecnológicos y digitales que abren la posibilidad de que las colectividades desborden la integración localista e incluyan la participación globalizada de sus miembros. Son comunidades de individuos donde los objetivos colectivos son puntuales y limitados a las afinidades materiales de las personas que buscan cambios parciales —educación, trabajo y salud, etc. - de la sociedad en general.

El proceso de individuación es la oportunidad que el individuo egocéntrico habitante de las ciudades del país se transforme en un individualismo social cholo y mestizo. Su transformación facilita la recuperación de lo colectivo andino, rescata la calle, el barrio, "sus habilidades y herramientas ciudadanas perdidas" y permite el tránsito a un individualismo en "genuina autonomía y capacidad de autoafirmación" (Bauman, 2005, p. 46). En realidad, este camino complejo solo puede realizarse como expresión 
de los movimientos reivindicativos que buscan cambios parciales de la sociedad, como punto de partida y empoderamiento de la comunidad de individuos.

La tercera posibilidad del individualismo contemporáneo es la gestación de un proceso de autonomía frente a la sociedad. El desarrollo de la autonomía individual y colectiva es precursor de inéditas formas de organización social. El individuo asume la capacidad para transformase en sujeto "afirmando su autonomía respecto a las instituciones de la sociedad" (Castells, 2012, p. 220). Los sujetos participan en las redes de comunidades desbordando los marcos societales, rechazan las instituciones existentes y buscan un nuevo contrato social, que compatibilice la libertad individual con la igualdad. En ese sentido, las comunidades se trastocan en "espacios de la autonomía" societal, porque aspiran modificar y erradicar la colonialidad de la sociedad en su conjunto.

La autonomía es el potencial que posibilita a los individuos convertirse en sujetos con objetivos al margen de las instituciones de la sociedad. Dinámica que se abre mediante la participación de las personas en las redes comunales locales, donde en libertad individual conjugan sus apegos autónomos con los demás. Las posibilidades que puedan ir más allá de la sociedad moderna se construyen por los sujetos individuales y colectivos en todas partes del mundo como "utopías reales" (Wright, 2014), sociedades "de coste marginal cero" (Ryfkin, 2014), y en las respuestas populares a la "crisis que estalló en 2008, primero en Estados Unidos y luego en Europa" (Castells, 2017, p. 292). La particularidad de América Latina subraya que el esfuerzo de indígenas, negros y mestizos en las comunidades devienen espacios autónomos "integrales" porque abordan todos los aspectos de la vida de las personas, desde las ideas, la producción, los alimentos, la salud hasta la justicia y el poder, destacan las experiencias de las Juntas de Buen Gobierno Zapatista, los Cabildos de Nasa del Cauca, las experiencias mapuches (Zibechi, 2015, p. 117). Experiencias fundadas en vínculos sociales "democráticos igualitarios" que posibilitan que el sujeto se desenvuelva híbridamente dentro de la sociedad y fuera de la sociedad.

Precisamente, como las instituciones existentes ya no pueden ordenar en forma simétrica las normas de la vida social, se abre la posibilidad que los individuos agrupados en comunidades puedan establecer un discurso y sentido diferente a la propia sociedad. Las posibilidades del proceso de autonomía solo pueden realizarse como expresión de los movimientos que aspiran al cambio del conjunto de la sociedad. Los movimientos de la sociedad -el ecologismo, el indígena, el feminismo, los derechos humanos y la igualdad social- son acciones colectivas transformadoras de los valores sobre los cuales se organizan las instituciones. Las personas en las comunidades autónomas de los movimientos de la sociedad gestan nuevos discursos fundados en la búsqueda de un horizonte histórico de sentido de un mundo diferente. Se trata de la aspiración del bienestar que beneficie a todos, en libertad individual, igualdad social y tome en cuenta 
el entorno de la tierra, de la demanda de una forma de vida digna, de buen vivir como se concibe en la cultura andina.

En general, el individualismo contemporáneo se revela como un proceso complejo y contradictorio, conlleva la coexistencia de sus múltiples formas, aunque supone la hegemonía del individualismo egocéntrico y abre las posibilidades de los procesos de individuación y autonomía societal.

\section{Referencias}

Adams, N. y Valdivia, N. (1991). Los otros empresarios. Ética de migrantes y formación de empresas en Lima. Lima: IEP.

Arellano, R. (2010). Al medio hay sitio. El crecimiento social según los estilos de vida. Lima: Arellano Marketing, Planeta.

Arellano, R. y Burgos, D. (2004). Ciudad de los reyes, de los Chávez, los Quispe... Lima: Epensa - Arellano Investigación de Marketing.

Bauman, Z. (2010). Mundo de consumo. Ética del individuo en la aldea global. Buenos Aires: Paidós.

Bauman, Z. (2005). Modernidad líquida. Buenos Aires: FCE.

BÉJAR, H. (1990). El ámbito intimo. (Privacidad, individualismo y modernidad). Madrid: Alianza.

Bonilla, H. (2005). "Cultura vs. Desarrollo en el contexto rural del área andina”. El futuro del pasado. Las coordenadas de la configuración de los andes. Lima: Pedagógico San Marcos - Instituto de Ciencia y Humanidades.

Bourdieu, P. (1980). "Le capital social. Notes provisoires", Actes de la Recherche en Sciences Sociales, Vol. 31, Consultado en abril de 2018 en http://www.persee.fr/ web/revues/home/prescript/article/arss_0335-5322_1980_num_31_1_2069

Bourricaud, F. (1953); (2012). Cambios en Puno. Estudios de sociología andina. Lima: IEP - IFEA.

Bourricaud, F. (1967), (1989). Poder y sociedad en el Perú. Lima: IEP - IFEA.

Castells, M. (2017). Otra economía es posible. Cultura y economía en tiempos de crisis. Madrid: Alianza.

Castells, M. (2012). Redes de indignación y esperanza. Los movimientos sociales en la era de internet. Madrid: Alianza.

Castells, M. (2009). Comunicación y poder. Madrid: Alianza.

Comisión de la Verdad y Reconciliación (2003). Informe final. Lima: CVR.

Contreras, C. (1996). Maestros, mistis y campesinos en el Perú rural del siglo XX. Documento de Trabajo $\mathrm{N}^{\circ} 80$, Lima: IEP. 
Cornejo, Antonio (1995). "Condición migrante e intertextualidad cultural: el caso de Arguedas". Revista de Crítica Literaria Latinoamericana, No 42: Lima-Berkeley.

Degregori, C. y Blondet, C. y Lynch, N. (1986). Conquistadores de un nuevo mundo. De invasores a ciudadanos en San Martín de Porres. Lima: IEP.

Dülmen, R. (2016). El descubrimiento del individuo 1500-1800. Madrid: Siglo XXI.

Dumont, L. (1987). Ensayos sobre el individualismo. Una perspectiva antropológica sobre la ideología moderna. Madrid: Alianza.

Durkheim, E. (1898). L'individualisme et les intellectuels. Les classiques des sciences sociales. Consultado en abril de 2018 en http://classiques. uqac.ca/classiques/ Durkheim_emile/sc_soc_et_action/texte_3_10/ individualisme.pdf.

Franco, C. (1991). Imágenes de la sociedad peruana: la otra modernidad. Lima: CEPES. Huber, L. (1998). Etnicidad y economía en el Perú. Documento de Trabajo No 83, Lima: IEP.

Lipovetsky, G. (1986). La era del vacio, ensayos sobre el individualismo contemporáneo. Barcelona: Anagrama.

MartucCelli, D. (2015). Lima y sus arenas. Poderes sociales y jerarquias culturales. Lima: Causes.

Maffesoli, M. (1990). El tiempo de las tribus. Barcelona: Icaria.

Mejía, J. (1994). "Individualismo y modernidad. Aspectos teóricos de lo público y lo privado”. Investigaciones Sociales, No 2, Lima: UNMSM.

Montoya, R. (2010). Porvenir de la cultura quechua en el Perú. Desde Lima, Villa El Salvador y Puquio. Lima: Oxfam -Coordinadora Andina de Organizaciones Indígenas-CONACAMI-UNMSM.

Matos, J. (2012). Estado desbordado y sociedad nacional emergente. Lima: Centro de Investigación de la Universidad Ricardo Palma.

Morin, E. y Ceruti, M. (2013). Nuestra Europa. ¿Qué podemos esperar?, ¿Qué podemos hacer? Barcelona: Barcelona.

Neira, H. (1993). "Huachafería: postura e impostura". Socialismo y Participación, No 63, Lima: CEDEP.

Seminario, B. (2015). El desarrollo de la economía peruana en la era moderna. Precios, población y producción desde 1700. Lima: Universidad del Pacífico.

PiketTy, T. (2014). El capital en el siglo XXI. México: FCE.

Portocarrero, G. (2007). "El silencio, la queja y la acción", Racismo y mestizaje y otros ensayos. Lima: Fondo Editorial del Congreso del Perú.

Quijano, A. (2011). "Bien vivir: entre el "desarrollo" y la des/colonialidad del poder", Ecuador debate, No 84: Quito.

Quijano, A. (2009). "Colonialidad del poder y subjetividad en América Latina”, en: Carmen Pimentel (Organizadora): Poder, ciudadania, derechos humanos y salud mental en el Perú. Lima: Cecosam. 
Quijano, A. (2001). "Entre La Guerra santa y la cruzada", América Latina en Movimiento, $\mathrm{N}^{\circ} 341$, Quito.

Quijano, A. (1980). "Lo cholo y el conflicto cultural en el Perú", en Dominación y cultura. Lo cholo y el conflicto cultural en el Perú. Lima: Mosca Azul Editores.

RyFкIn, J. (2014). La sociedad de coste marginal cero. El internet de las cosas y el eclipse del capitalismo. Barcelona: Paidós.

Riofrío, G. y Driant, J. (1987). ¿Qué vivienda han construido? Nuevos problemas en viejas barriadas. Lima: CIDAP-IFEA-Tarea.

Simmel, G. (1986). El individualismo y la sociedad. Barcelona: Península.

Svampa, M. (2016). Debates latinoamericanos. Indigenismo, desarrollo, dependencia y populismo. Cochabamba: CEDIB.

Touraine, A. (2011). Después de la crisis. Por un futuro sin marginación. Barcelona: Barcelona.

Wright, E. (2014). Construyendo utopias reales. Madrid: Akal.

Zibechi, R. (2017). Movimientos sociales en América Latina El "mundo otro" en movimiento. Bogotá: Desde Abajo.

Zibechi, R. (2015). "Movimientos antisistémicos y descolonialidad". Rafael Sandoval y otros, Pensar desde la resistencia anticapitalista y la autonomía. México: CIESAS. 